\title{
UMA ANÁLISE DA DISTRIBUIÇÃO REGIONAL DO FUNDEB EM 2007 E 2017
}

\author{
Kalinca Léia Becker
}

\section{INTRODUÇÃO}

O acesso ao sistema gratuito de educaçáo básica é um direito de todos os brasileiros, conforme o art. 208 da Constituição Federal de 1988, a qual também estabelece que a União, os Estados e os municípios devem destinar $25 \%$ da arrecadação com impostos para manutenção e desenvolvimento do sistema público de ensino.

O Fundo de Manutenção e Desenvolvimento da Educação Básica e de Valorização dos Profissionais da Educação (Fundeb), instituído em 2007 com vigência até 31 de dezembro de 2020, foi criado para garantir um investimento mínimo por aluno e também promover a distribuição dos recursos em todo o território nacional.

Assim, ao longo de 2020, discutiu-se a possibilidade de tornar esse fundo permanente, e também a alteração da lógica de distribuição e alocação dos recursos. Isso porque a distribuiçẫo do fundo se dava entre os municípios do mesmo estado, de modo que os recursos ficavam concentrados naqueles com maior arrecadação. Além disso, as outras fontes municipais de financiamento da educação não eram levadas em consideração na distribuição dos recursos, e a complementação da Uniāo era realizada em nível estadual. Dessa forma, tanto municípios ricos como pobres de um mesmo estado recebiam o mesmo valor por aluno. Isso poderia ser considerado um desvio de focalizaçáo da política do Fundeb se considerarmos que o objetivo é direcionar os recursos para os municípios que mais precisam.

Diante disso, este texto faz uma breve análise da distribuição do Fundeb por aluno, comparando com o produto interno bruto (PIB) per capita dos municípios brasileiros em 2007 e 2017.

\section{FUNDEB}

A Lei no 9.424, de 1996, definiu o Fundo de Manutenção e Desenvolvimento do Ensino Fundamental e de Valorizaçáo do Magistério (Fundef), destinado inicialmente ao ensino fundamental e médio. Em 2007, foi substituído pelo Fundeb, conforme a Lei

1. DOI: http://dx.doi.org/10.38116/brua24art2

2. Professora na Universidade Federal de Santa Maria (UFSM); e pesquisadora do Programa de Pesquisa para o Desenvolvimento Nacional (PNPD) na Diretoria de Estudos e Políticas Regionais, Urbanas e Ambientais (Dirur) do Ipea. 
no 11.494 , que estendeu o fundo a todas as redes de ensino fundamental, incluindo educaçáo infantil e educação para jovens e adultos (EJA).

O Fundeb consiste em uma conta estadual na qual os municípios depositam $20 \%$ da receita arrecadada com oito tributos específicos, ${ }^{3}$ e a União complementa os recursos dos fundos que ficaram com o menor valor por aluno. $\mathrm{O}$ valor da conta do Fundeb estadual é distribuído aos municípios de acordo com o número de alunos matriculados na rede pública de ensino básico, multiplicado por um fator de ponderação. ${ }^{4}$ Alguns estudos apontam evidências de que o fundo contribuiu para aumentar a eficiência da administração escolar dos municípios, em virtude da descentralização dos recursos, embora esse resultado não seja observado para todos os municípios (Sousa, Cribari-Neto e Stosic, 2005; Gonçalves e França, 2013).

Em uma conta específica para educação, os municípios devem destinar no mínimo 5\% do valor arrecadado com os oito tributos do Fundeb, a fim de cumprir o que está estabelecido na Constituição Federal de 1988, na qual estados e municípios devem destinar pelo menos $25 \%$ de sua receita orçamentária para a manutenção e o desenvolvimento do sistema público de educação básica. Nessa conta também devem ser depositados no mínimo $25 \%$ da receita arrecadada com os demais impostos. ${ }^{5}$ Os arts. 70 e 71 da Lei de Diretrizes e Bases da Educação Nacional (LDB) definem como o município pode despender os recursos dessa conta a fim de investir na rede pública de ensino. No caso dos recursos do Fundeb, esta definição está nos arts. 21, 22 e 23 da Lei no 11.494/2007.

\section{DISTRIBUIÇÃO REGIONAL DO FUNDEB E DO PIB DOS MUNICÍPIOS (2007 E 2017)}

A figura 1 apresenta a distribuição regional do Fundeb por aluno e do PIB per capita dos municípios em 2007 e 2017. Os valores do Fundeb são disponibilizados pela Secretaria do Tesouro Nacional (STN), e o número de matrículas foi obtido no Censo Escolar, realizado pelo Instituto Nacional de Estudos e Pesquisas Educacionais Anísio Teixeira (Inep). O PIB per capita é disponibilizado pelo Instituto Brasileiro de Geografia e Estatística (IBGE). Os valores estáo em logaritmo e, no caso de 2007, foram deflacionados para preços de 2017, utilizando-se como deflator o Índice Nacional de Preços ao Consumidor (INPC). Para os municípios sem informação, atribuiu-se o valor médio da microrregiáo.

Em 2007, a média do Fundeb por aluno era $\mathrm{R} \$ 2.665,11$ e, em 2017, esse valor era $\mathrm{R} \$ 5.552,48$, o que representa um aumento de $108 \%$. O valor mínimo investido por aluno passou de $\mathrm{R} \$ 284,29 \mathrm{em} 2007$ para $\mathrm{R} \$ 2.298,47 \mathrm{em} 2017$. O intervalo entre o valor mínimo e o máximo do Fundeb nos municípios, para o cálculo dos intervalos dos mapas, reduziu-se de 4,80 para 2,68, o que, em termos gerais, pode ser um indicativo de que houve uma melhora na distribuição dos recursos do fundo em termos da média nacional nos dez anos do Fundeb.

3. São eles: Imposto sobre Produtos Industrializados (IPI), Imposto sobre Circulação de Mercadorias e Serviços (ICMS), Lei Kandir, Imposto Territorial Rural (ITR), Fundo de Participação dos Municípios (FPM), Imposto sobre a Propriedade de Veículos Automotores (IPVA), Fundo de Participação dos Estados e do Distrito Federal (FPE) e Imposto sobre Transmissão Causa Mortis e Doação (ITCMD).

4. 0 fator de ponderação representa quanto vale cada matrícula. Por exemplo, uma matrícula no ensino integral precisa de mais recursos em relação a uma matrícula no ensino parcial. Atualmente há dezenove fatores de ponderação, e a base de cálculo é uma matrícula no ensino fundamental urbano nas séries iniciais. Disponível em: <https://bit.ly/2TDzm5z>.

5. Quais sejam: Imposto Predial e Territorial Urbano (IPTU), Imposto sobre a Transmissão de Bens Imóveis (ITBI), Imposto de Renda Retido na Fonte (IRRF) e Imposto sobre Serviços (ISS). 
FIGURA 1

Mapas de distribuição do Fundeb por aluno e PIB per capita (2007 e 2017)

1 A - Fundeb por aluno (2007)

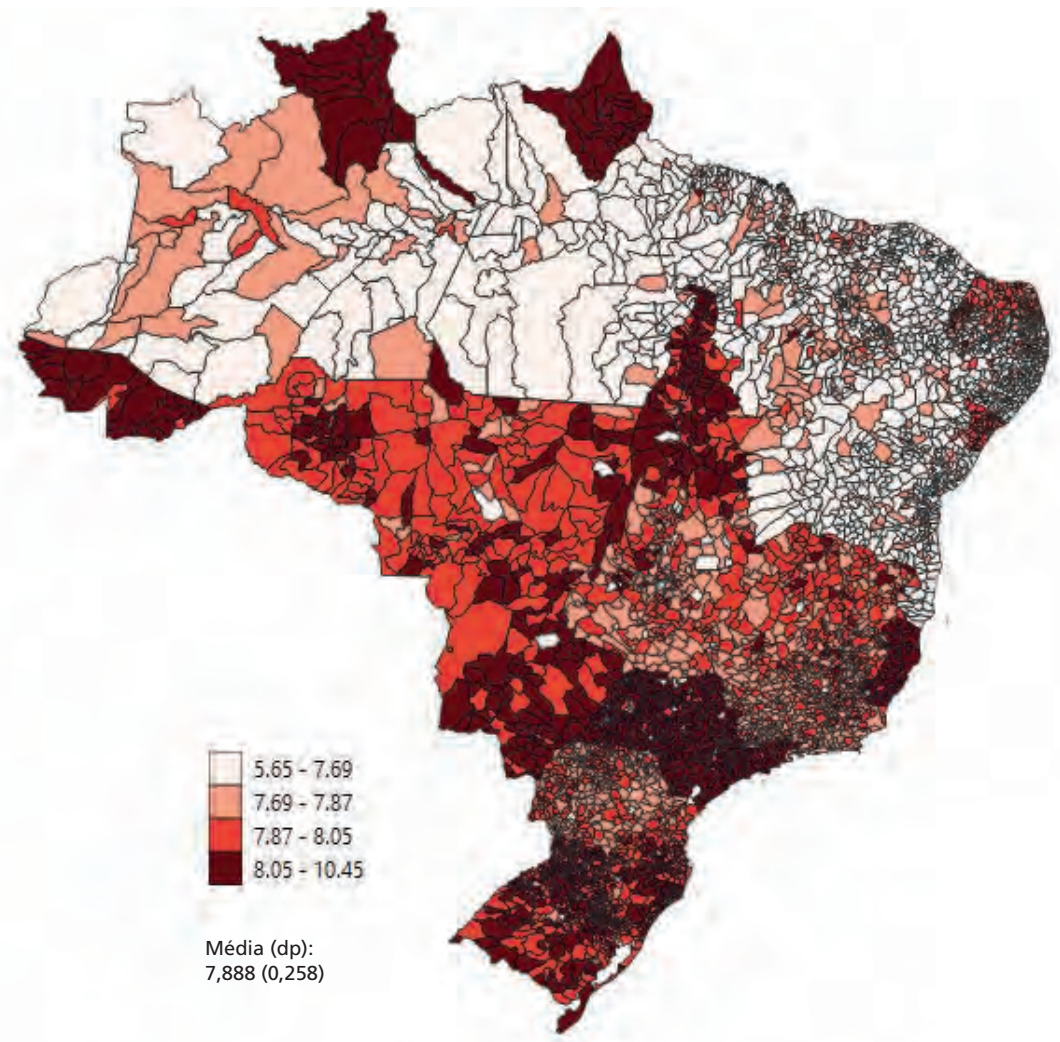

1B - PIB per capita (2007)

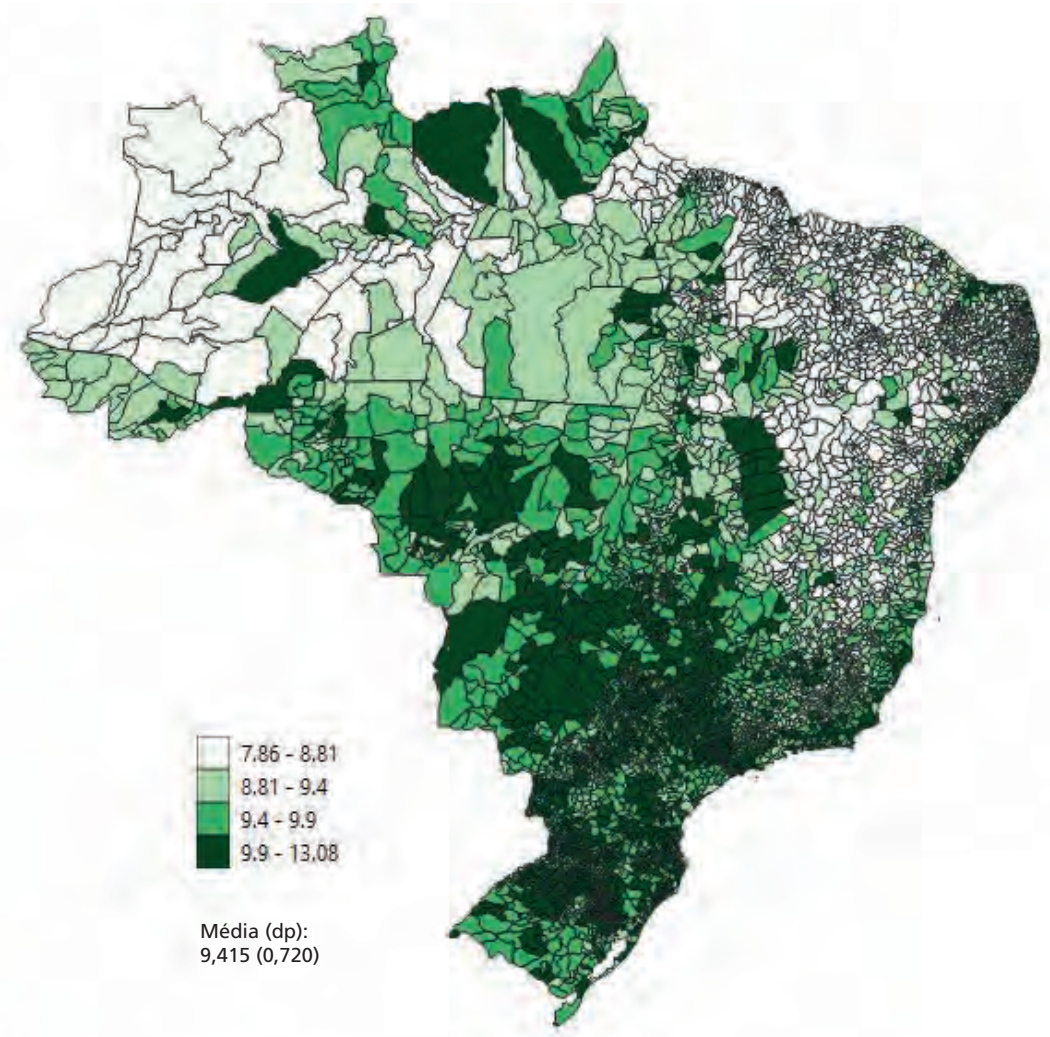




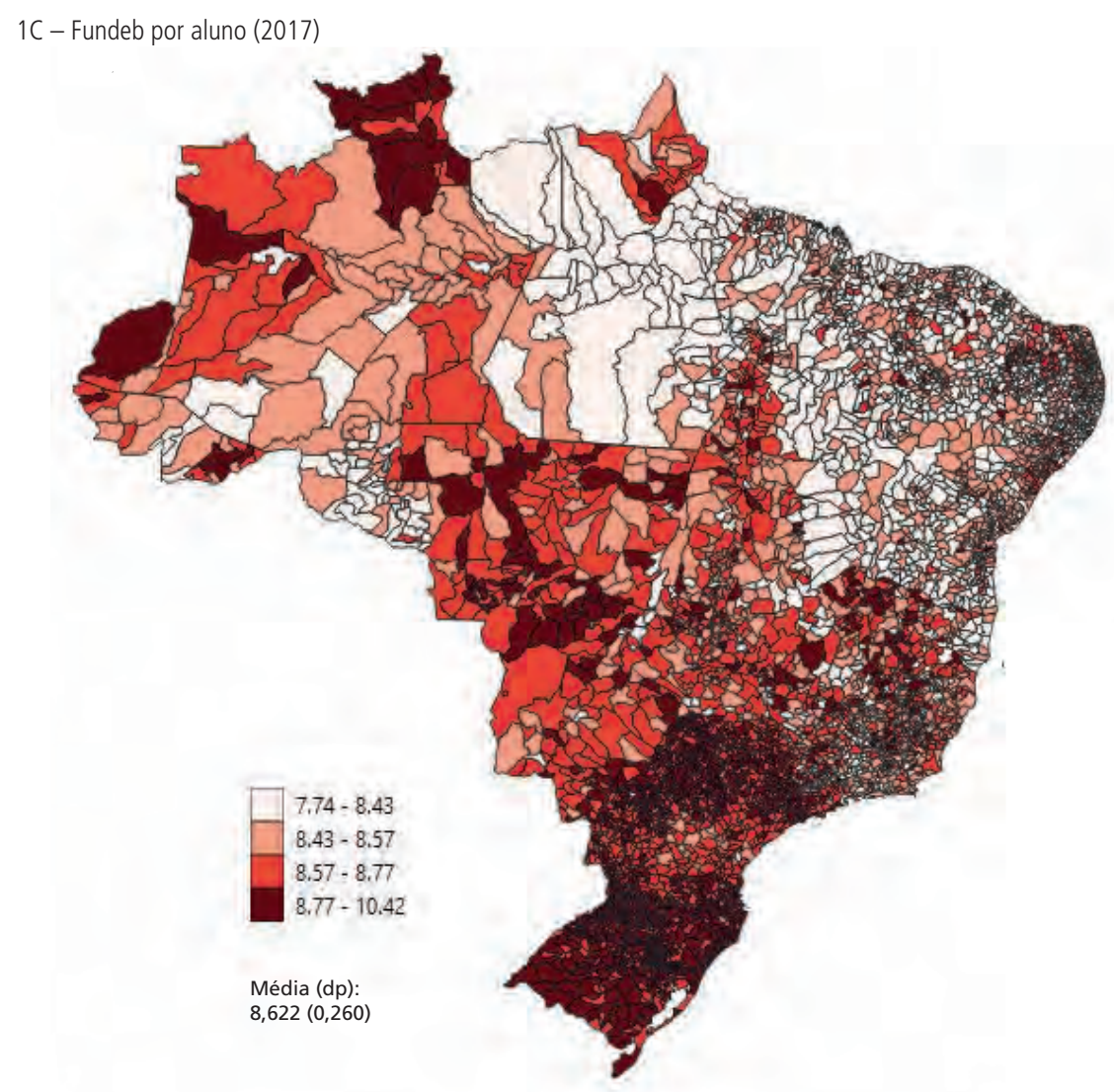

1D - PIB per capita (2017)

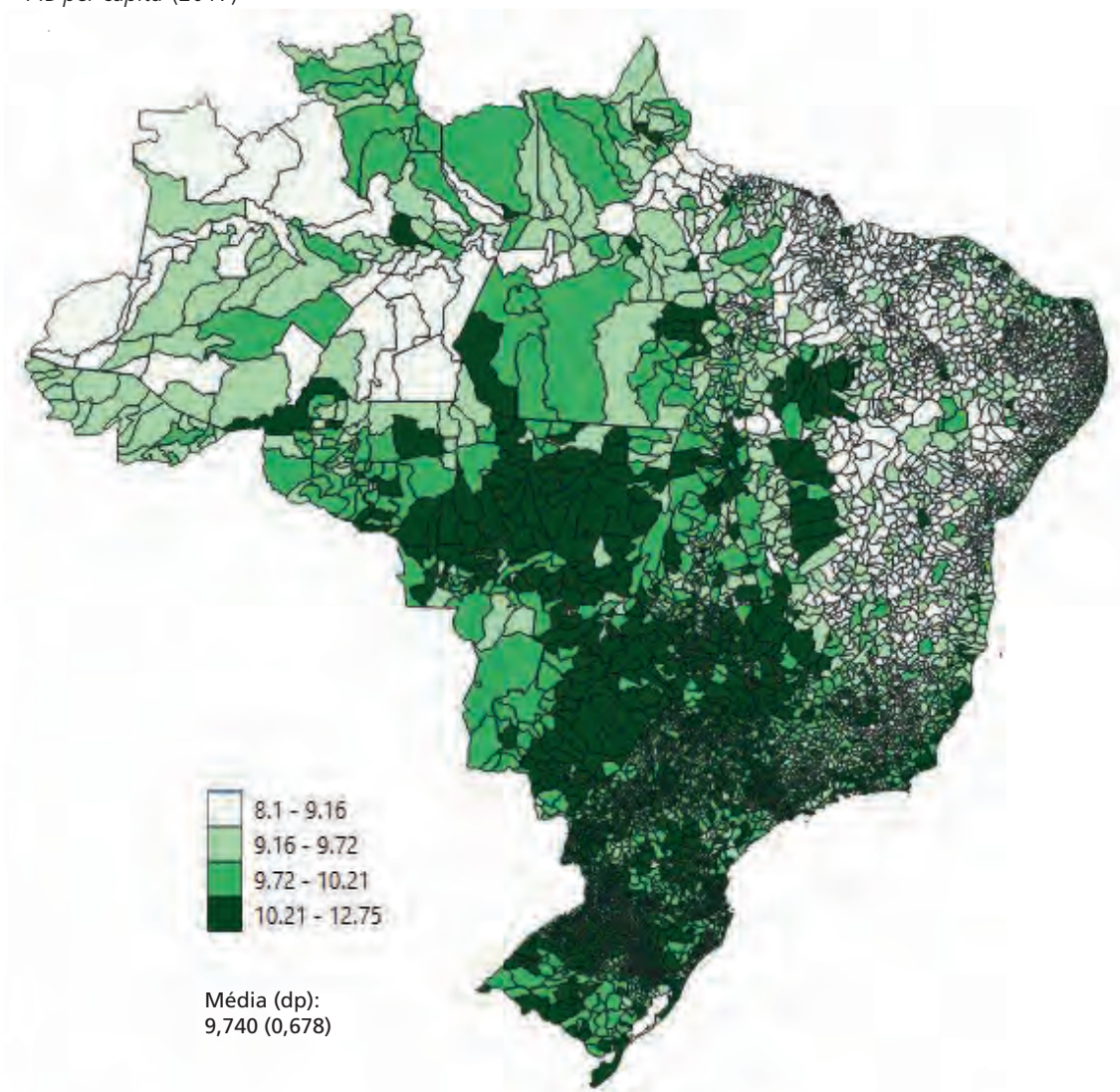

Fonte: STN, Inep e IBGE.

Obs.: 1. Os valores do Fundeb por aluno e do PIB per capita estão medidos em logaritmo. Os valores entre parênteses são o desvio-padrão da média (dp).

2. Figura cujos leiaute e textos não puderam ser padronizados e revisados em virtude das condições técnicas dos originais (nota do Editorial). 
Nos mapas da figura 1, contudo, observa-se que, em ambos os anos, os maiores valores do Fundeb por aluno estão nos municípios dos estados das regiōes Sul e Sudeste e os menores valores encontram-se nas regiōes Norte e Nordeste, que coincidem também com a distribuição dos valores do PIB per capita.

A fim de analisar de forma mais precisa as concentraçóes dos valores do Fundeb por aluno e do PIB per capita no território nacional, a figura 2 apresenta os mapas de clusters LISA (Local Indicator of Spatial Association) e o indicador I de Moran, que permitem identificar a autocorrelaçáo local e os padróes de associaçáo espacial (clusters espaciais). O sinal positivo da estatística I de Moran, quando significativo, indica que os dados estão concentrados nas regióes; por sua vez, o sinal negativo indica dispersão nos dados. Quanto mais próximo de 1 , maior a concentração, e quanto mais próximo de -1 , mais dispersos estão os dados (Almeida, 2012). Os mapas de clusters LISA permitem observar se municípios com alto (ou baixo) valor do Fundeb por aluno são rodeados também por municípios com alto (ou baixo) valor do Fundeb por aluno. Assim, os mapas permitem identificar quatro categorias de associação espacial: alto-alto, baixo-baixo, alto-baixo e baixo-alto. Da mesma forma, foram construídos mapas de cluster para o PIB per capita.

\section{FIGURA 2}

Mapas de clusters do Fundeb por aluno e PIB per capita (2007 e 2017)

2A - Fundeb por aluno (2007)

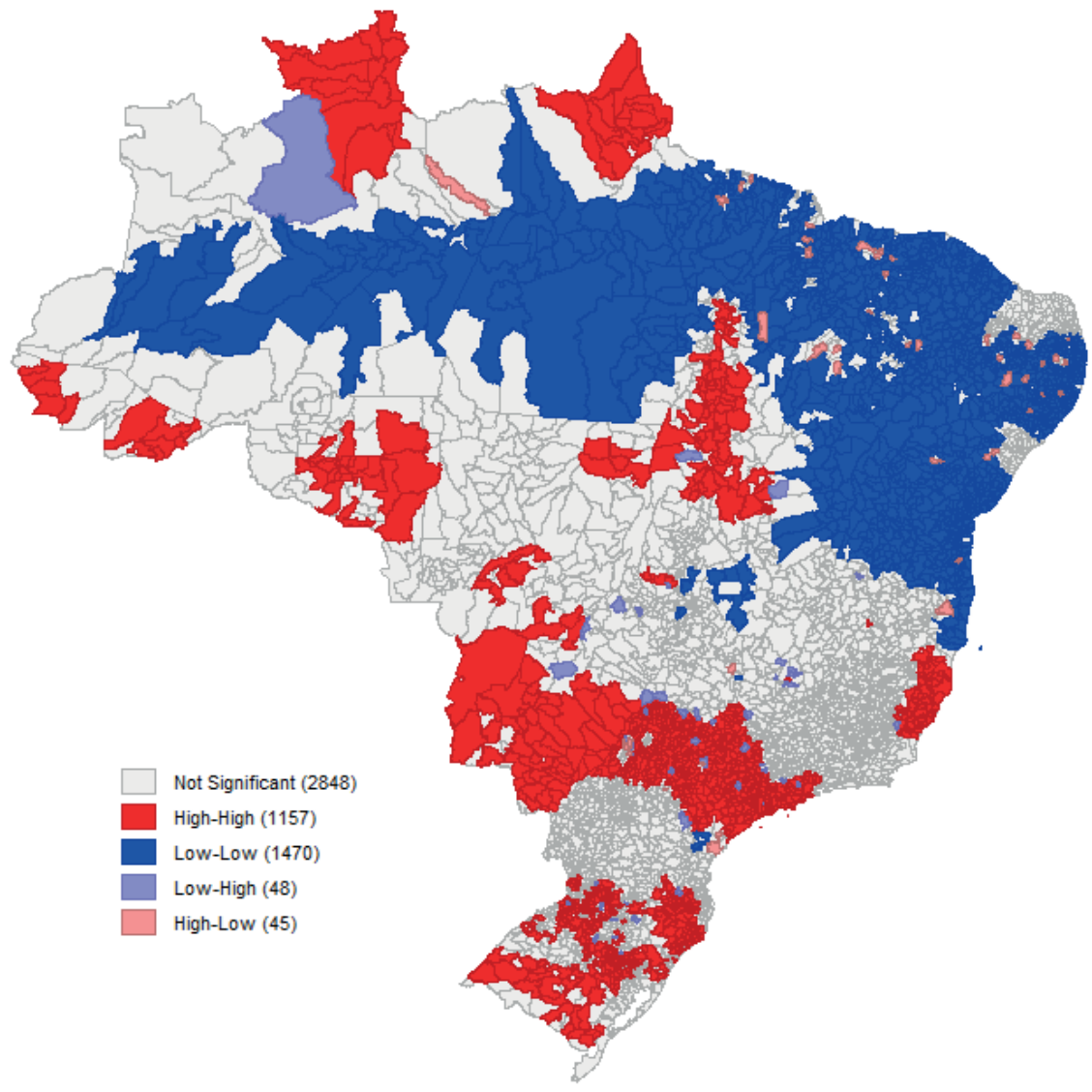




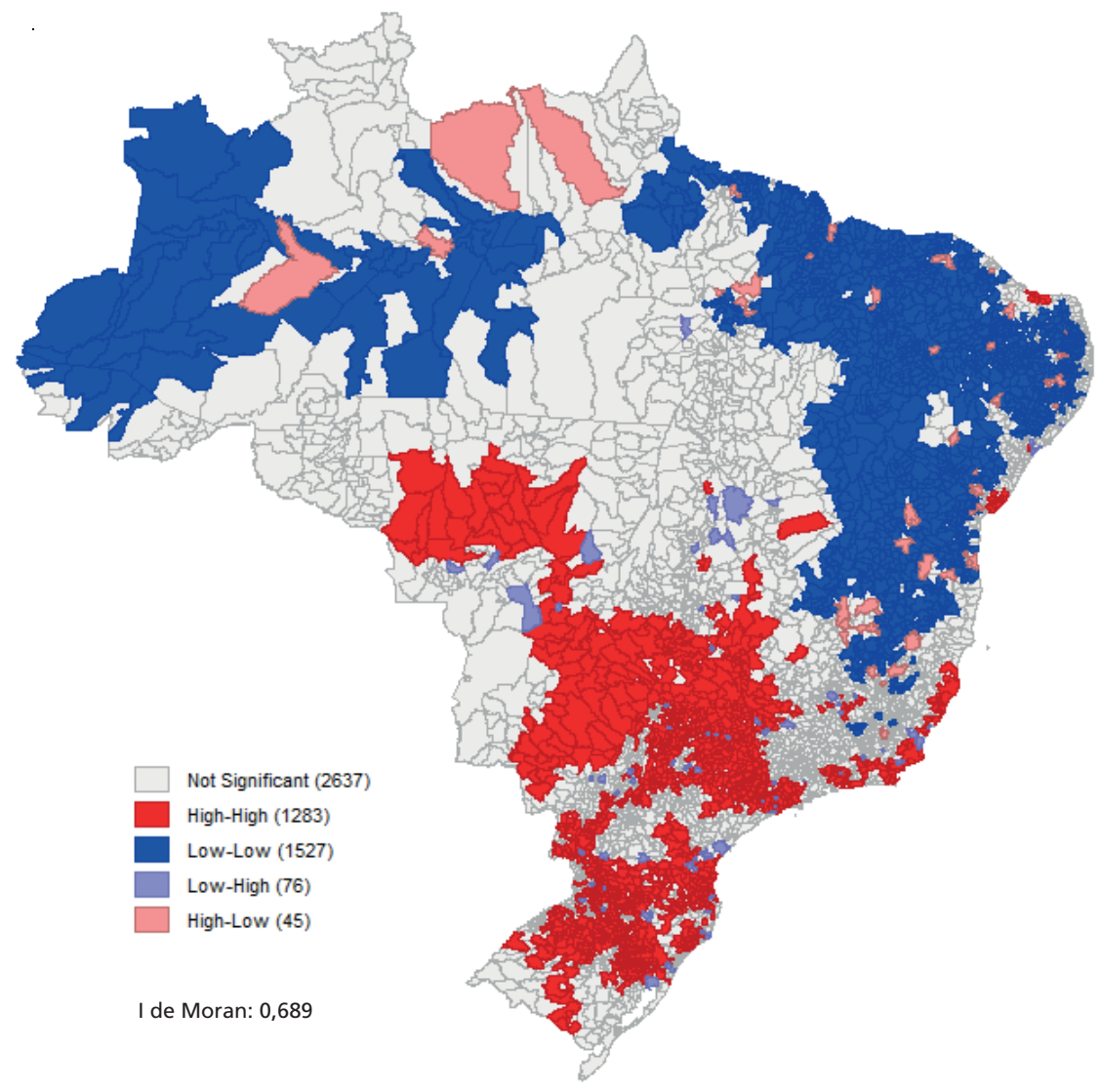

$2 C$ - Fundeb por aluno (2007)

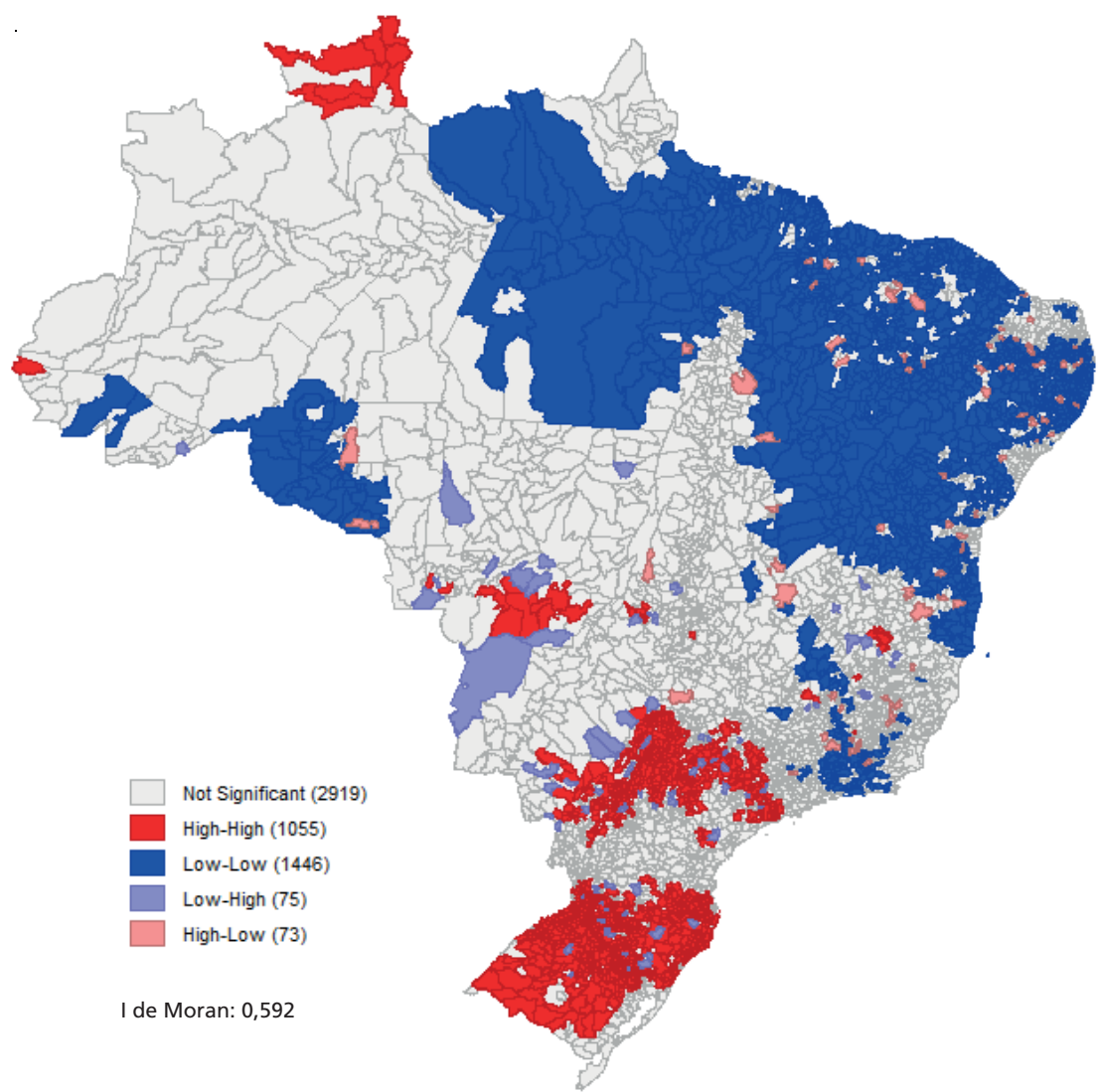




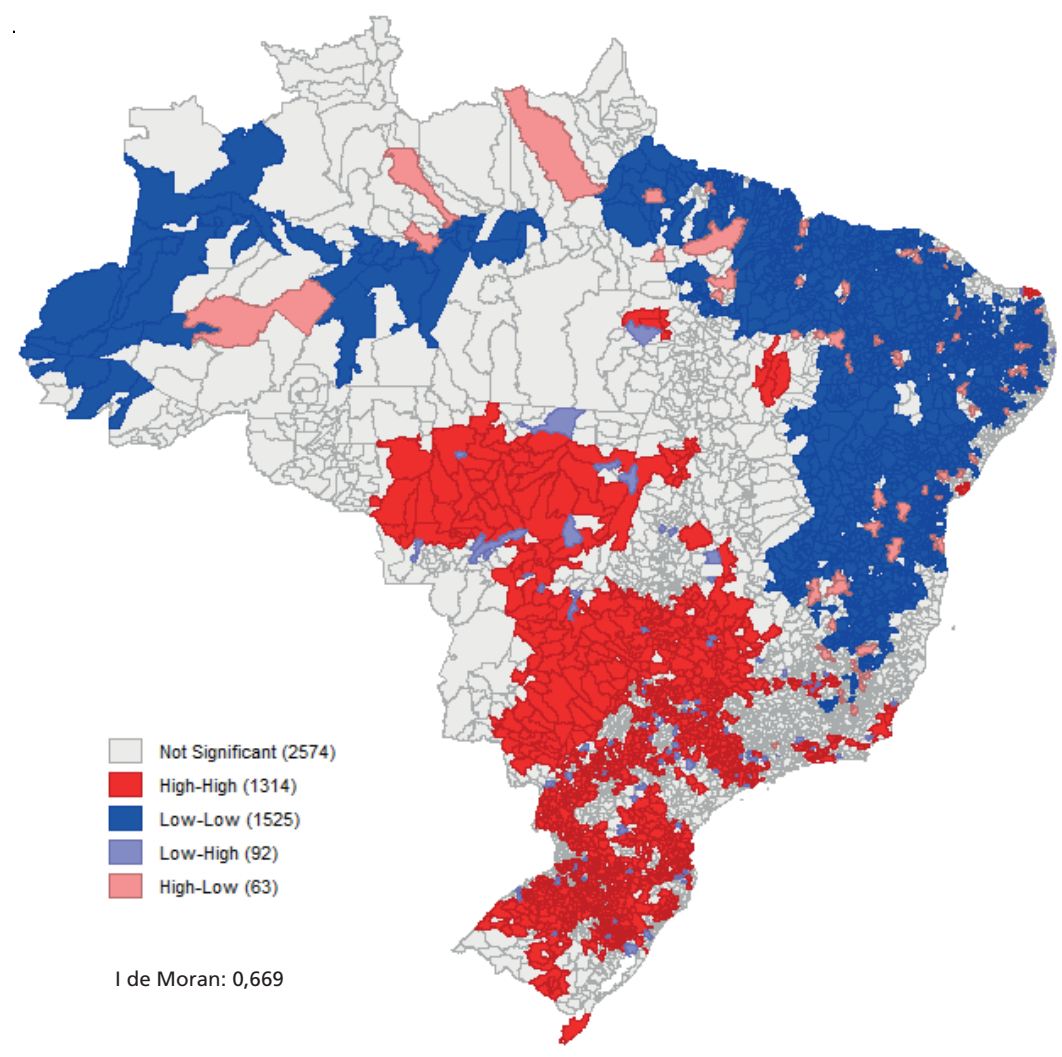

Fonte: STN, Inep e IBGE.

Obs.: Figura cujos leiaute e textos não puderam ser padronizados e revisados em virtude das condiçôes técnicas dos originais (nota do Editorial).

Os resultados confirmam a análise visual da figura 1, de modo que o sinal positivo da estatística I de Moran mostrou que os dados estão concentrados nas regióes. Os clusters do tipo alto-alto estão, principalmente, nos estados do Sul e Sudeste, o que revela que municípios com elevado Fundeb por aluno são rodeados por municípios que também possuem elevado valor do fundo. No entanto, os clusters do tipo baixo-baixo estão nas regióes Norte e Nordeste.

Havia um cluster do tipo baixo-baixo nos municípios do estado do Amazonas em 2007, porém tal concentração não foi significativa em 2017. Da mesma forma, o cluster do tipo alto-alto nos municípios do estado do Mato Grosso do Sul, observado em 2007, não se mostrou significativo em 2017. O número de municípios no cluster alto-alto no estado de São Paulo reduziu-se entre 2007 e 2017 e, no caso do Rio Grande do Sul, houve um aumento nesse número.

Assim, pode-se observar que, ao longo dos dez anos do Fundeb, houve algumas alteraçóes na alocação dos recursos dentro dos estados, porém não houve grandes mudanças da distribuição do fundo considerando todo o território nacional.

Além disso, a disponibilidade de recursos para o Fundeb parece coincidir com a riqueza dos estados, mensurada por meio do PIB per capita. Nesse sentido, a figura 3 apresenta o mapa de cluster LISA bivariado, de modo a observar se municípios com alto (ou baixo) valor do Fundeb por aluno sáo rodeados por municípios com alto (ou baixo) PIB per capita. 
FIGURA 3

Mapas de clusters bivariados Fundeb por aluno versus PIB per capita $3 \mathrm{~A}-2007$

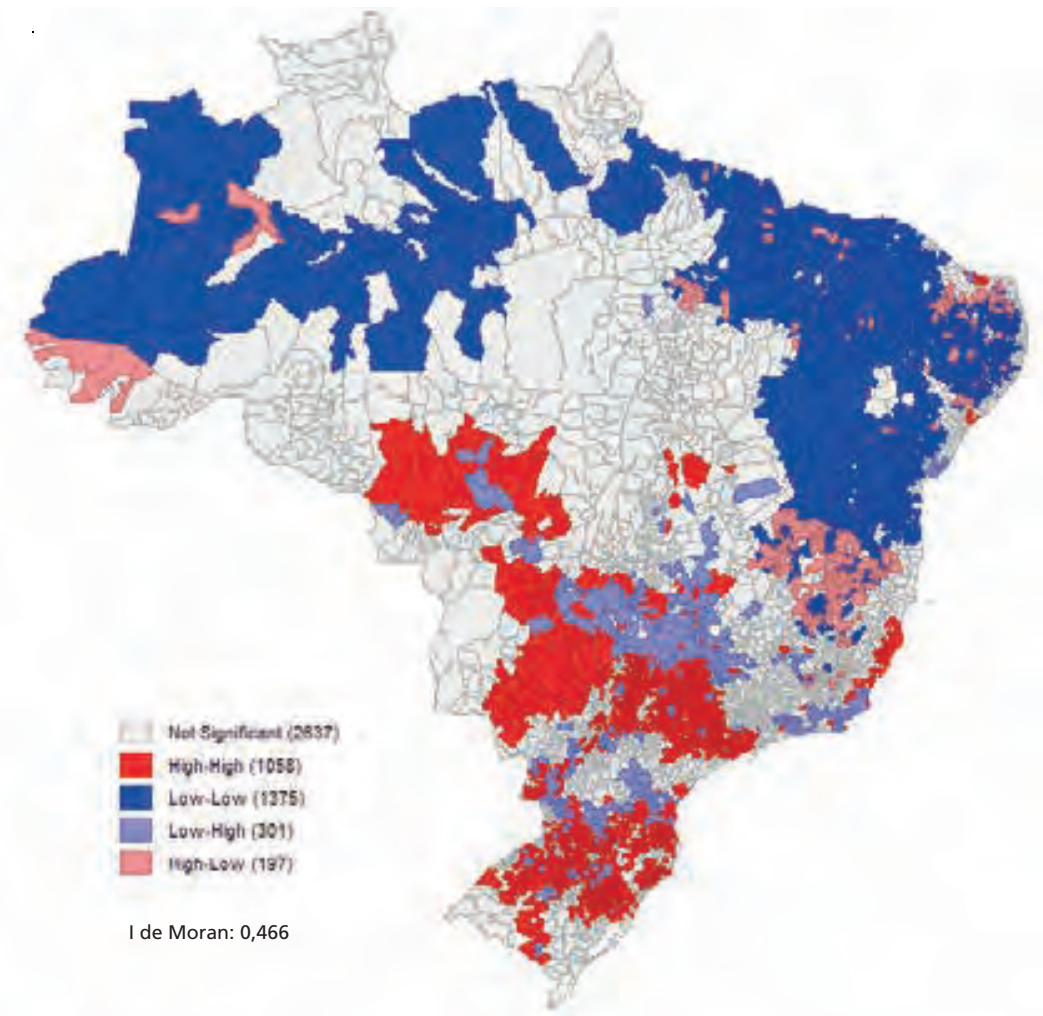

$3 B-2017$

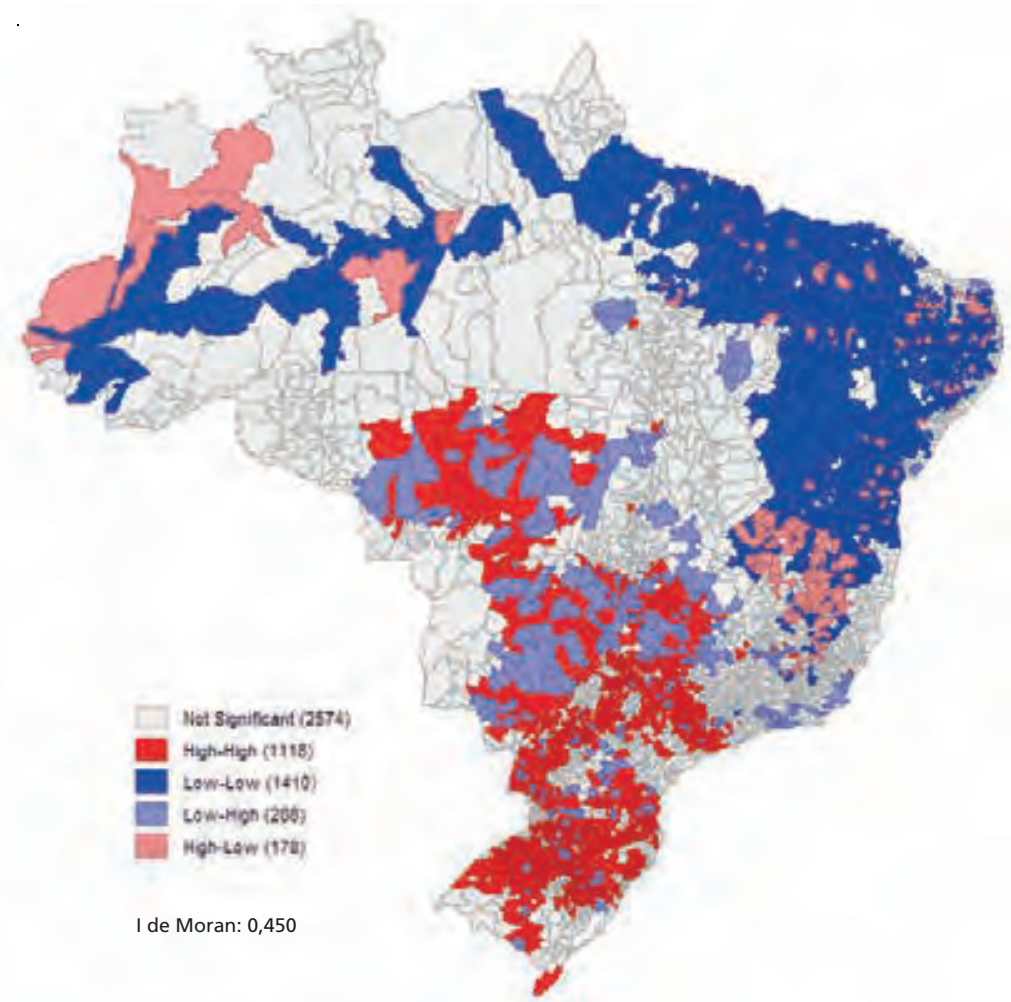

Obs.: Figura cujos leiaute e textos não puderam ser padronizados e revisados em virtude das condições técnicas dos originais (nota do Editorial). 
O indicador I de Moran foi 0,47 em 2007 e 0,45 em 2017 e, novamente, a maior parte dos clusters identificados foi do tipo alto-alto nos estados do Sul e Sudeste e do tipo baixo-baixo no Norte e Nordeste, o que é um indicativo de que os recursos do Fundeb se concentraram nas regiôes mais ricas do território nacional.

Esse resultado está de acordo com a lógica de distribuição de recursos do Fundeb, que, atualmente, se dá entre os municípios do mesmo estado e, dessa forma, estados mais ricos disponibilizam mais recursos para o fundo.

\section{CONCLUSÃO}

O Fundeb, instituído em 2007 com vigência até 31 de dezembro de 2020, tem como principais objetivos garantir um investimento mínimo por aluno e também promover a distribuição dos recursos em todo o território nacional. Passados mais de dez anos da implementação da política, na proximidade do término da vigência do fundo tal como foi desenhado, foi importante analisar a necessidade ou náo de aprimoramentos dos mecanismos de gestáo e alocaçáo para uma possível continuidade. Diante disso, este texto fez uma breve análise da distribuição do Fundeb por aluno, comparando com o PIB per capita dos municípios brasileiros em 2007 e 2017.

Os resultados evidenciaram que os recursos do Fundeb se concentraram nas regiôes mais ricas do território nacional, o que provavelmente decorreu da lógica de distribuição do fundo que se dava entre os municípios do mesmo estado. Assim, aqueles com maior arrecadação disponibilizavam mais recursos para a conta estadual do Fundeb. Além disso, a complementação de recursos da União para os fundos que ficaram com o menor valor por aluno era feita no nível estadual e, dessa forma, municípios pobres em estados com elevado valor do fundo náo recebiam a complementação. Por sua vez, municípios ricos em estados que recebiam tal complementação também eram beneficiados. Vale ressaltar que outras fontes de arrecadação municipal para o financiamento da educação ${ }^{6}$ não eram levadas em consideraçáo na distribuição dos recursos para os municípios no mesmo estado, de modo que todos os municípios recebiam o mesmo valor por aluno.

Assim, considerar tais recursos disponíveis para investimentos em educaçáo nas contas municipais e realizar a complementação da União em nível local e por redes de ensino podem ser formas de melhorar o mecanismo de distribuição dos recursos Fundeb. Diante disso, o Decreto no 10.656, de 22 de março de 2021, tornou o fundo permanente, e foi adotado um modelo híbrido de distribuição dos recursos, no qual municípios pobres em estados ricos também passam a receber o complemento da União, sempre que o valor anual total por aluno não atingir o mínimo nacional.

\section{REFERÊNCIAS}

ALMEIDA, E. Econometria espacial aplicada. Campinas: Editora Alínea, 2012.

GONÇALVES, F. de O.; FRANÇA, M. T. A. Eficiência na provisão de educação pública municipal: uma análise em três estágios dos municípios brasileiros. Estudos Econômicos, v. 43, n. 2, p. 271-299, 2013.

SOUSA, M. C. S.; CRIBARI-NETO, F.; STOSIC, B. D. Explaining DEA technical efficiency scores in an outlier corrected environment: the case of public services in Brazilian municipalities. Brazilian Review of Econometrics, v. 25, n. 2, p. 289-315, 2005.

6. 0 art. 212 da Constituição Federal de 1988 determina que os estados e municípios devem destinar pelo menos 25\% de sua receita orçamentária para a manutenção e o desenvolvimento do sistema público de educação básica. Assim, em uma conta municipal específica para educação deve-se destinar, no mínimo, 5\% do valor arrecadado com os oito tributos que compõem o Fundeb, e $25 \%$ dos demais, conforme descrito na seção 2 deste texto. 
